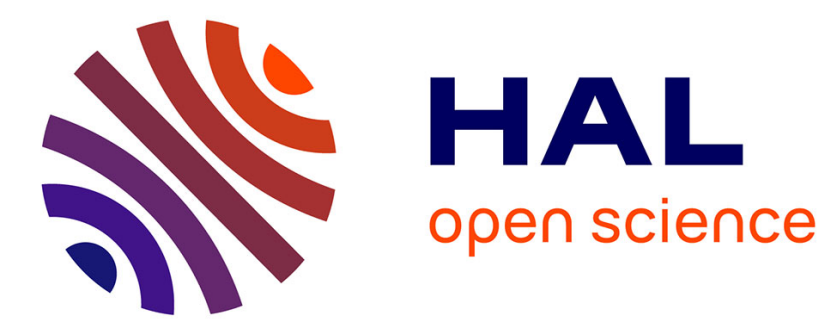

\title{
Recent trends in magnetic bubble-devices
}

\author{
C.J.M. Rooymans
}

\section{To cite this version:}

C.J.M. Rooymans. Recent trends in magnetic bubble-devices. Revue de Physique Appliquée, 1975, 10 (3), pp.179-181. 10.1051/rphysap:01975001003017900 . jpa-00243901

\section{HAL Id: jpa-00243901 https://hal.science/jpa-00243901}

Submitted on 1 Jan 1975

HAL is a multi-disciplinary open access archive for the deposit and dissemination of scientific research documents, whether they are published or not. The documents may come from teaching and research institutions in France or abroad, or from public or private research centers.
L'archive ouverte pluridisciplinaire HAL, est destinée au dépôt et à la diffusion de documents scientifiques de niveau recherche, publiés ou non, émanant des établissements d'enseignement et de recherche français ou étrangers, des laboratoires publics ou privés. 
Classification

Physics Abstracts

$8.550-8.560$

\title{
RECENT TRENDS IN MAGNETIC BUBBLE-DEVICES (*)
}

\author{
C. J. M. ROOYMANS \\ Philips Research Laboratories, Eindhoven, The Netherlands \\ (Reçu le 3 décembre 1974, accepté le 8 janvier 1975)
}

\begin{abstract}
Résumé. - Nous présentons un résumé sur la technologie et les méthodes de fonctionnement des dispositifs à bulles magnétiques. Un fonctionnement adéquat de ces dispositifs exige une succession de dépôts de couches minces de grenat monocristallin, de nickel-fer, de silice et de matériaux conducteurs, certains dépôts étant effectués selon des configurations spécifiques. Nous soulignons la nécessité de simplifier la construction pour obtenir un degré suffisant de miniaturisation. Nous décrivons les démarches qui peuvent être entreprises à cette fin.
\end{abstract}

\begin{abstract}
A concise survey is given on the technology and operational aspects of magnetic bubble devices. A proper functioning of such devices implies a special sequence of thin film layers of monocristalline garnet, permalloy, silica and conductor material, some only present in specific patterns. Attention is given to the necessity of simplifying the construction in order to get a sufficient degree of miniaturization. Novel approaches are outlined to overcome the problems related herewith.
\end{abstract}

In a previous paper by Maréschal and coworkers [1] the problems in relation to the growth of crystals and amorphous materials for magnetic bubble devices have been extensively described. It is obvious however, that the availability of high-quality crystals of the orthoferrites and of perfect epitaxial garnet films or amorphous layers is only a prerequisite, albeit a necessary one, for the operation of magnetic devices based on cylindrical domains. Hence in this concise contribution I want to deal with some aspects which are of crucial importance in the construction of a useful bubble-device [2].

In figure $1 \mathrm{a}$ simplified and schematic cross-section is given of a typical device chip. We see the crystalline substrate of $\mathrm{Gd}_{3} \mathrm{Ga}_{5} \mathrm{O}_{12}$, around $400 \mu \mathrm{m}$ in thickness, and the $5 \mu \mathrm{m}$ thick epitaxially-grown magnetic garnet film in which the bubbles occur, on top of this a thin

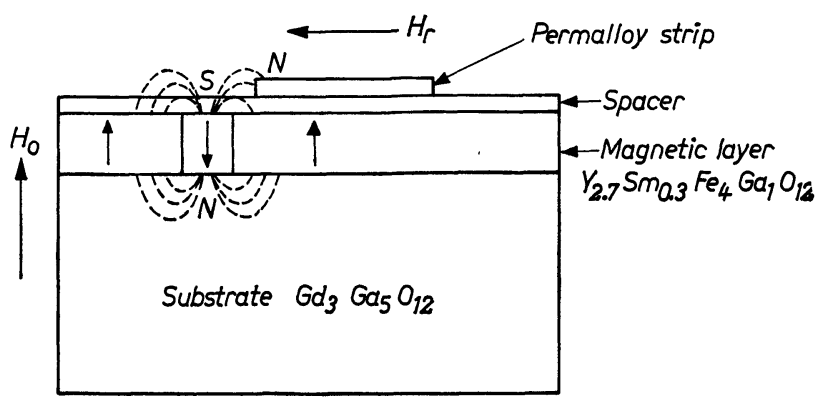

FIG. 1. - Schematic cross-section of bubble device chip.

(*) Communication présentée à la journée d'étude sur les Matériaux Magnétiques pour l'Electronique, Orsay, mars 1974. spacer of around $1 \mu \mathrm{m}$, made of silica or another inert oxide and deposited preferably by R. F. sputtering. This layer is necessary to attain an optimal distance between the epifilm and the soft-magnetic permalloy layer ( $0.4 \mu \mathrm{m}$ thick) on top. Between the garnet layer and the spacer a $50 \AA$ thick permalloy layer can be present to suppress the occurrence of hard bubbles [3]. This layer as well as the top-layer of permalloy can be produced by several techniques, e. g. vacuum deposition, sputtering, and electrochemical processes. In the permalloy top layer a complicated pattern is etched, $\mathrm{T}$ and $\mathrm{Y}$ bars for instance, to realize the functions as generation, propagation, switching and annihilation of the bubbles, in combination with an in-plane rotating magnetic field, the so called field-access method [4]. Proper operation of these functions can be done with pulse signals to be given by small conductor stripes and again fabricated by an evaporation or sputtering process followed by chemical etching or ion-milling with the help of suitable masks. Detection of the bubbles is another problem, nowadays this is generally realized by the magnetoresistance effect, fortunately possible with the same permalloy-composition as used for the other functions [5]. The requirements in thickness and dimensions, however, are not identical : while the optimal positioning of the detector in the whole overlay-arrangement is not as critical as the other permalloy structures, it should be as close to the magnetic film as possible. This would imply another overlay-pattern, and thus another masking step. The consequences of such a structure are schematically outlined in figure 2 ; of course other arrangements are also possible. We see a structure built up with the help 


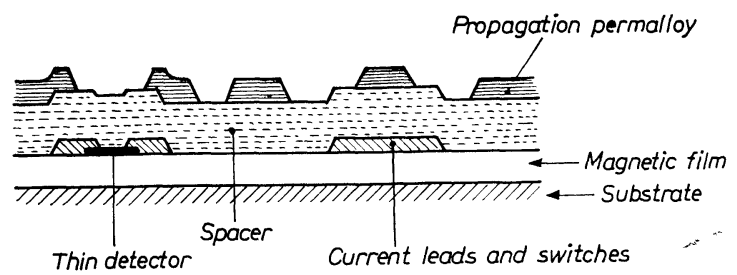

Fig. 2. - Overlay arrangement in cross-section for field-access bubble device with thin detector.

of 3 to 4 different masking steps, followed by suitable technological procedures. Even more steps are necessary to ensure good adherence between the various layers. If we then realize that the characteristics of the permalloy pattern have dimensions which are about half the diameter of the bubbles present, the problem of getting properly functioning bubble-devices is clear. How to realize such a device based on, for instance, $5 \mu \mathrm{m}$ bubbles with a sufficient accuracy and yield when we have to use so many masks with the necessity of carefully aligning them and such a variety of technological and chemical procedures. The rapid progress so far has been possible by using the experience available in the manufacturing of semiconductor circuits, but $5 \mu \mathrm{m}$ diameter bubbles are, however, certainly not the limit. The requirements put forward by the need for an as-high information density as possible, and by economic considerations, go to much smaller bubble dimensions, namely, down to one micron or less. The masks can then be made by X-ray lithography or electron beam procedures instead of the conventional photolithography now used, but we should then minimize the number of masks in the first place. The loss in accuracy due to the aligning procedures in such a stack forms one of the main restrictions to the overall-yield and also sets a practical limit to the miniaturization process.

A first step toward simplification was given by the introduction of the chevron expander [6]. In this way the signal can be sufficiently amplified to allow a realization of the detection function on the same level and simultaneously with the other permalloy elements used for propagation, etc. The expansion of the bubble by chevron structures before sensing to assure a sufficient signal diminishes the storage density, but this disadvantage is largely overruled by the greater ease in fabricating the structure as a whole [7]. A next step is to make the conductor leads also out of the same permalloy composition. This approach, however, has its drawbacks, the resistance of these wires is higher than the gold ones, and hot spots and corrosion effects easily occur. Quite another approach has been studied by Druyvesteyn et al. [8]. These authors have shown the feasibility of using the sense of the rotation of the in-plane drive field for a proper operation of the above mentioned control functions. Current leads are superfluous in this design a laboratory model is shown in figure 3 . The leads for the detection function - a thick detector has been used - can be deposited in a rather

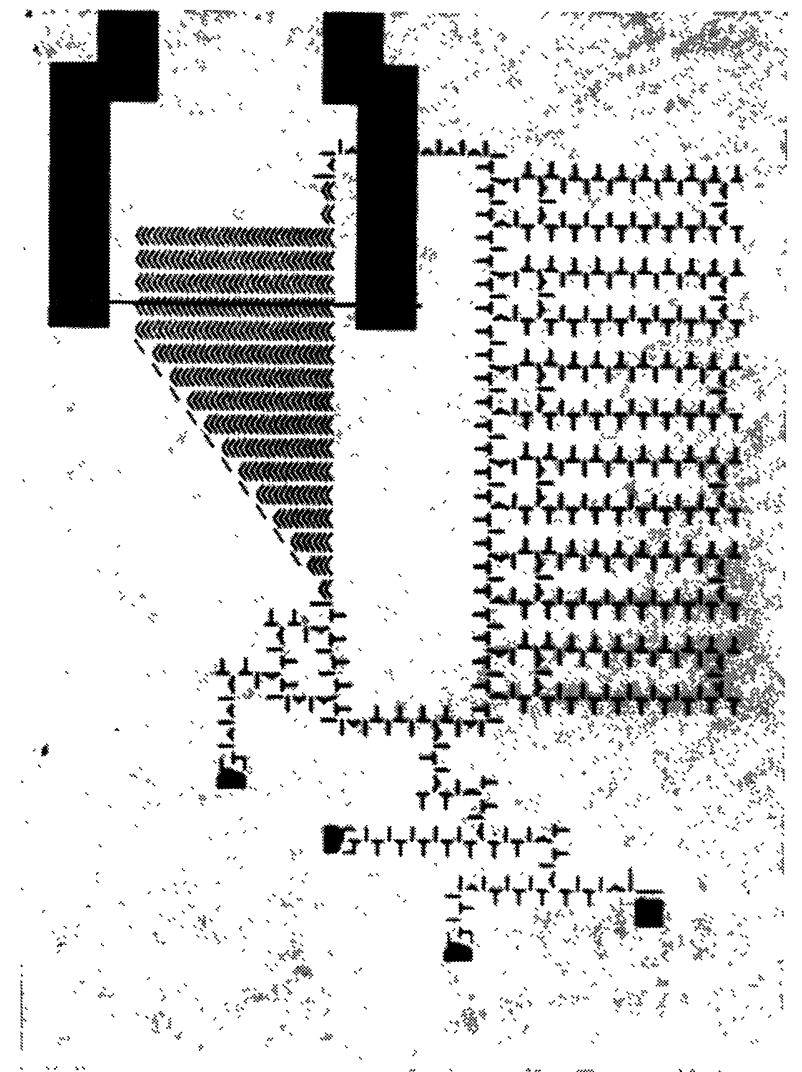

FIG. 3. - Lay-out of a c. w./c. c. w. arrangement (according to ref. [8]).

coarse way, as short circuiting is not possible due to the absence of connections between the permalloy elements. Such a design can therefore be realized by one mask for the desired permalloy pattern. A schematic cross-section of such a design is given in figure 4 . In such a way submicron size features are a realizable

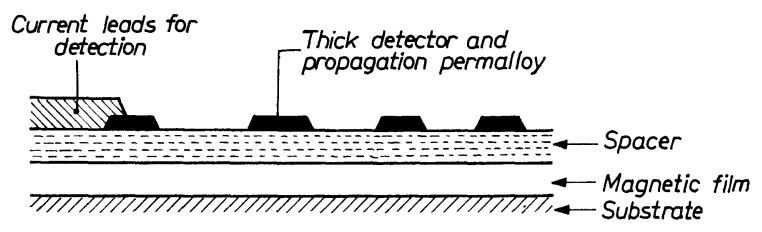

FIG. 4. - Overlay arrangement in cross-section for field access bubble device with thick detector in c.w./c.c.w. operation.

proposition. Electron beam technology can be used for the overlay-mask. Shift registers with submicron bubbles $(0.8 \mu \mathrm{m})$ have already been successfully fabricated on garnet films [9] with characteristic line widths of 0.3 to $0.5 \mu \mathrm{m}$. From this short survey it is obvious that a real control of the various technological steps is required for the successful operation of these devices at an acceptable cost. An extensive review on production, cost and market has recently been published by Curtiss [10]. A comparison with other memory components has been made by Wieder and Tomlinson [11]. 


\section{References}

[1] Maréschal, J., Challeton, D., Daval, J., Ferrand, B and GAY, J. L., "Matériaux pour dispositifs utilisant le déplacement de domaines magnétiques », Revue Phys. Appl. 9 (1974) 865.

[2] Rooymans, C. J. M., « Current problems in bubble memory materials » 2nd European Electro-optics Markets and Technology Conference, Montreux 1974.

[3] Takahashi, M., Nishida, H., Kobayashi, T. and Sugita, Y. « Hard-bubble free garnet epitaxial films : the garnetpermalloy composite structure ", J. Phys. Soc. Japan 34 (1973) 416.

LIN, Y. S. and KeEFE, G. E., « Suppression of hard bubbles by a hard permalloy layer », Appl. Phys. Lett. 22 (1973) 603-4.

[4] Bonyhard, P. I., DanylchuK, I., Kish, D. E. and SMITH, J. L., « Applications of bubble devices 》 IEEE Trans. Mag. 6 (1970) 447-51.

[5] Strauss, W., "Detection of cylindrical magnetic domains ", J. Appl. Phys. 42 (1971) 1251-7.
[6] Archer, J. L., Tocci, L., George, P. K. and Chen, T. T., «Magnetic Bubble Domains Devices », IEEE Trans. Mag. 8 (1972) 695-700.

[7] Bobeck, A. H., Danylchuk, I., Rossol, F. C. and STrAuss, W., « Evolution of bubble circuits processed by a single mask level», IEEE Trans. Mag. 9 (1973) 474-80.

[8] Druyvesteyn, W. F., KuYpers, F. A., DE Niet, E. and VAN DE ENDEN, A. W. M., " An all-permalloy bubble memory with control functions based on drive-field operation », IEEE Trans. Mag. 10 (1974) 757-60.

[9] Hu, H. L., Hatzakis, M., Giess, E. A. and Plaskett, T. S., «Shift registers with submicron magnetic bubbles on garnet films ", to be published.

[10] CurTiss, D. A., "Magnetic bubble technology», October 1973, Ovum, Ltd London.

[11] Wieder, H. H. and Tomirnson, J. L., « Magnetic Bubble Domain Computer Memory Components», Technical Note Naval Electronics Laboratory Center, San Diego, Cal. January 1974. 